Article

\title{
Cisplatin Decreases ENaC Activity Contributing to Renal Salt Wasting Syndrome
}

\author{
Antonio G. Soares ${ }^{1,+}{ }^{+}$, Elena Mironova ${ }^{1}$, Crystal R. Archer ${ }^{1}$, Jorge Contreras ${ }^{1}$, \\ James D. Stockand ${ }^{1, *}$ and Tarek Mohamed Abd El-Aziz ${ }^{1,2,+}(\mathbb{D}$ \\ 1 Department of Cellular and Integrative Physiology, University of Texas Health Science Center at San \\ Antonio, 7703 Floyd Curl Dr, San Antonio, TX 78229-3900, USA; soaresa@uthscsa.edu (A.G.S.); \\ mironova@uthscsa.edu (E.M.); ArcherC@uthscsa.edu (C.R.A.); contrerasj12@uthscsa.edu (J.C.); \\ mohamedt1@uthscsa.edu (T.M.A.E.-A.) \\ 2 Zoology Department, Faculty of Science, Minia University, El-Minia 61519, Egypt \\ * Correspondence: stockand@uthscsa.edu \\ + These authors contributed equally to this work.
}

Received: 30 June 2020; Accepted: 27 July 2020; Published: 1 August 2020

\begin{abstract}
Cisplatin (CDDP) is an important anticancer drug. A common side effect of CDDP is renal salt and water-wasting syndrome (RSWS). The origin of RSWS is obscure. Emerging evidence, though, suggests that broad inhibition of sodium transport proteins by CDDP may result in decreases in tubular reabsorption, causing increases in sodium and water excretion. In this sense, CDDP would be acting like a diuretic. The effect of $\mathrm{CDDP}$ on the epithelial $\mathrm{Na}^{+}$channel $(\mathrm{ENaC})$, which is the final arbiter fine-tuning renal $\mathrm{Na}^{+}$excretion, is unknown. We test here whether CDDP affects $\mathrm{ENaC}$ to promote renal salt and water excretion. The effects of CDDP and benzamil (BZM), a blocker of ENaC, on excretion of a sodium load were quantified. Similar to BZM, CDDP facilitated renal $\mathrm{Na}^{+}$excretion. To directly quantify the effects on $\mathrm{ENaC}$, principal cells in split-open tubules were patch clamped. CDDP, at doses comparable to those used for chemotherapy $(1.5 \mu \mathrm{M})$, significantly decreased ENaC activity in native tubules. To further elaborate on this mechanism, the dose-dependent effects of $\mathrm{CDDP}$ on mouse ENaC ( $\mathrm{mENaC}$ ) heterologously expressed in Chinese Hamster Ovary $(\mathrm{CHO})$ cells were tested using patch clamping. As in native tubules, CDDP significantly decreased the activity of $\mathrm{mENaC}$ expressed in $\mathrm{CHO}$ cells. Dose-response curves and competition with amiloride identified $\mathrm{CDDP}$ as a weak inhibitor of $\mathrm{ENaC}$ (apparent $\mathrm{IC}_{50}=1 \mu \mathrm{M}$ ) that competes with amiloride for inhibition of the channel, weakening the inhibitory actions of the latter. Such observations are consistent with $\mathrm{CDDP}$ being a partial modulator of $\mathrm{ENaC}$, which possibly has a binding site that overlaps with that of amiloride. These findings are consistent with inhibition of ENaC by CDDP contributing to the RSWS caused by this important chemotherapy drug.
\end{abstract}

Keywords: Deg/ENaC channels; renal sodium excretion; hypertension; diuretic; pseduohypoaldosteronism; chemotherapy

\section{Introduction}

Cisplatin (cis-diamminedichloroplatinum (II), or CDDP) and related compounds, including carboplatin and oxaliplatin, are platinum-containing drugs commonly used in chemotherapy. These drugs are powerful chemotherapy agents because of their ability to bind DNA and inhibit replication [1-3]. While important for chemotherapy, this class of drugs causes debilitating side effects, including renal salt and water-wasting syndrome (RSWS) and nephrotoxicity. It is unclear how these two complications of CDDP treatment are related. It is believed that the nephrotoxicity caused by 
CDDP results from DNA adduct formation, peroxidation of cell membranes, mitochondria dysfunction and apoptosis [2,4]. The origin of the RSWS caused by CDDP is more obscure.

Emerging evidence suggests that the RSWS caused by CDDP may result from accumulation in and dependent effects on the tubular epithelial cells, leading to an increase in urine output associated with natriuresis. CDDP is concentrated in proximal tubular epithelial cells via transport across the serosal membrane on the organic cation transporter 2 (OCT2) [5]. CDDP is secreted across the luminal membrane of proximal tubule epithelial cells and, consequently, concentrated in the urine in antiport to sodium via the multidrug and toxin extrusion protein 1 (SLC47A1) [6]. CDDP is elevated in the plasma and kidneys of mice lacking SLC47A1 [6]. In possible complement to the action in the proximal tubule, effects on epithelial cells in the loop of Henle or the distal nephron to include the collecting duct system have not been excluded.

In addition to damaging cells via direct actions on DNA, CDDP, independent of the effects on DNA, also binds to and is a general inhibitor of sodium transport proteins, including $\mathrm{Na}^{+} / \mathrm{K}^{+}$-ATPase $[7,8]$. Inhibition of such transport proteins in the kidney would cause diuresis associated with generalized salt wasting. Moreover, CDDP in rodents reduces the expression of aquaporin 2 (AQP2) and $3[9,10]$. Reduced expression of these two aquaporins, which set the water permeability of the distal nephron, could result in diuresis. However, this diuresis would be expected to be associated with dilute urine, which does not seem to be the case for CDDP-induced RSWS. Nonetheless, CDDP appears to decrease the activity of several proteins in the kidney involved in salt and water excretion. It is possible that the DNA-independent effects of CDDP on renal transport proteins could contribute to the RSWS caused by this drug.

The epithelial $\mathrm{Na}^{+}$channel $(\mathrm{ENaC})$ is a sodium-selective ion channel expressed in the luminal plasma membranes of late distal convoluted tubule, connecting tubule and collecting duct principal cells [11]. The coordinated action of ENaC and AQP2 in principal cells sets the sodium and water permeability of the collecting duct and, as such, act as the final arbiters, fine-tuning renal salt and water excretion. Inhibitors of $\mathrm{ENaC}$, including amiloride and triamterene, are diuretics because they increase urine output as a function of increased sodium excretion [12]. It is unknown if CDDP affects ENaC. Blockers of $\mathrm{ENaC}$ though, including amiloride, function at high concentrations as general inhibitors of sodium transport proteins [13]. This is reminiscent of CDDP as possibly being a broad-spectrum inhibitor of sodium transport proteins. Moreover, it is worth noting that the guanidinium cation at the center of ENaC blockers, like benzamil (BZM) and amiloride, shares some similarity with the molecular structure and geometry of cisplatin [14]. Moreover, several heavy metals, including $\mathrm{Cd}^{2+}$, $\mathrm{Cu}^{2+}, \mathrm{Hg}^{2+}, \mathrm{Ni}^{2+}, \mathrm{Pb}^{2+}$ and $\mathrm{Zn}^{2+}$, are known to decrease the activity of $\mathrm{ENaC}$ [15]. It currently is unknown if ionized platinum affects $\mathrm{ENaC}$.

Based on the understanding that CDDP causes RSWS, is concentrated in urine, has a general inhibitory effect on sodium transport proteins and has some chemical similarity with the guanidinium core of $\mathrm{ENaC}$ blockers, and that heavy metals affect the activity of $\mathrm{ENaC}$, and that inhibitors of $\mathrm{ENaC}$ cause a natriuresis and diuresis similar to that caused by CDDP, we test here if CDDP affects ENaC activity and whether such action potentially could contribute to the RSWS caused by this widely used chemotherapy drug. Findings showed that CDDP causes a natriuresis similar to the ENaC blocker, $\mathrm{BZM}$. In isolated tubules, CDDP rapidly decreases $\mathrm{ENaC}$ activity. In a heterologous expression system, CDDP decreases the activity of $\mathrm{ENaC}$ in a dose-dependent manner in a way that is competitive with the effects of amiloride. Together, these results are consistent with CDDP being a partial inhibitor of $\mathrm{ENaC}$, with inhibition of this key renal ion channel possibly contributing to the RSWS caused by CDDP.

\section{Results}

\subsection{CDDP Increases Urinary Sodium Excretion}

Male mice were housed socially at three mice/cage with free access to water and food. After 2 days, mice received an $\mathrm{Na}^{+}$load $(100 \mu \mathrm{L}, 0.9 \% \mathrm{NaCl}$ solution) plus treatment with CDDP, BZM or a vehicle. 
Excretion of this sodium load was then followed over the next four hours. Figure 1 shows the cumulative excretion of an $\mathrm{Na}^{+}$load at 2 and $4 \mathrm{~h}$ following the injection of $100 \mu \mathrm{L}$ of a $0.9 \% \mathrm{NaCl}$ solution with BZM $(1.4 \mathrm{mg} / \mathrm{kg}$, intraperitoneal, i.p.), CDDP $(25 \mathrm{mg} / \mathrm{kg}$, i.p. $)$ and a vehicle. At $2 \mathrm{~h}$, the BZM group had significantly greater $\mathrm{Na}^{+}$excretion compared with the saline-injected control group. At the $4 \mathrm{~h}$ time point, $\mathrm{Na}^{+}$excretion was significantly greater in the CDDP and BZM groups compared with the control, with CDDP and BZM not being different. As expected, these results are consistent with CDDP, like BZM, facilitating $\mathrm{Na}^{+}$excretion.

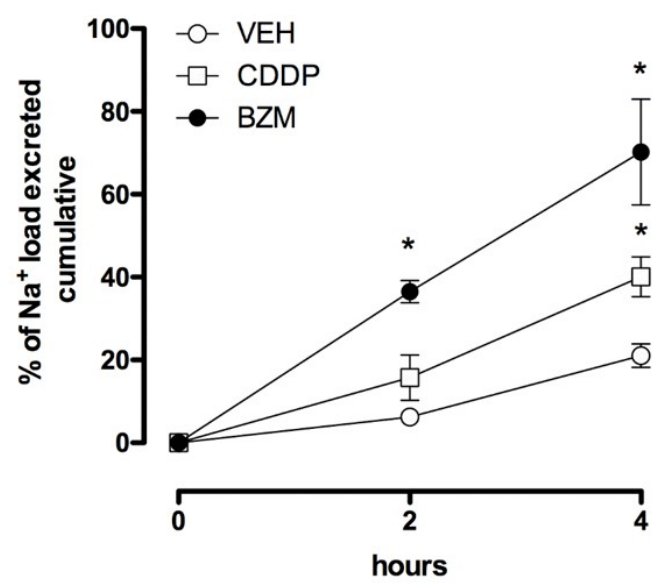

Figure 1. Cisplatin (CDDP) is natriuretic. Summary graph showing cumulative $\mathrm{Na}^{+}$excretion in mice that received an $\mathrm{Na}^{+}$load and treatment with cisplatin (CDDP, the black circles, where $n=5$ independent trials with three mice per trial), benzamil (BZM, the white squares, where $n=5$ independent trials with three mice per trial) or the vehicle (VEH, the white circles, where $n=5$ independent trials with three mice per trial) over a $4 \mathrm{~h}$ period. Treatment with BZM significantly increased $\mathrm{Na}^{+}$excretion at both the $2 \mathrm{~h}$ and $4 \mathrm{~h}$ time points. Treatment with CDDP significantly increased excretion at the $4 \mathrm{~h}$ time point, where BZM and CDDP were not different. ${ }^{*} p<0.05$ vs. VEH group.

\subsection{CDDP Reduces ENaC Activity in Split-Open Tubules}

Split-open tubules isolated from the kidneys were prepared for single-channel patch clamp electrophysiology in the cell-attached configuration. Figure 2 shows representative continuous current traces from the patch clamped luminal plasma membranes of principal cells in isolated split-open tubules from the $\mathrm{C} 57 \mathrm{Bl} / 6$ mouse. When $\mathrm{ENaC}$ activity was recorded in naïve tubules, the addition of CDDP rapidly reduced channel activity $\left(\mathrm{NP}_{\mathrm{o}}, 1.098 \pm 0.19\right.$ vs. $0.3725 * \pm 0.0917$, before and after CDDP treatment, respectively, ${ }^{*} p<0.05$ vs. Before). Figure $2 \mathrm{~A}, \mathrm{~B}$ show representative traces ((A), with before above and after below) and summary effects (B), respectively, of the actions of CDDP $(1.5 \mu \mathrm{M})$ on $\mathrm{ENaC}$ activity. These results are consistent with $\mathrm{CDDP}$ decreasing $\mathrm{ENaC}$ activity.

\subsection{CDDP Is a Partial Inhibitor of $E N a C$}

Chinese Hamster Ovary $(\mathrm{CHO})$ cells expressing $\mathrm{mENaC}$ were patch clamped in the whole-cell configuration under voltage clamp conditions in the presence and absence of amiloride. Similar to the $\mathrm{ENaC}$ blocker amiloride, $\mathrm{CDDP}$ reduced $\mathrm{mENaC}$ activity in $\mathrm{CHO}$ cells in a dose-dependent manner. As reported in Figure 3, macroscopic mENaC currents were reduced with an $\mathrm{IC}_{50}$ of $0.46 \pm 0.10 \mu \mathrm{M}$ and $1.0 \pm 0.18 \mu \mathrm{M}$ for amiloride and CDDP, respectively. Maximal responses on mENaC activity, calculated as an inhibition percentage (Emax), were $91.9 \pm 0.80$ vs. $56.6 \pm 4.2 \%$ for amiloride and CDDP, respectively, with the latter being significantly lower than the former. These results demonstrate that $\mathrm{CDDP}$ is a partial inhibitor of $\mathrm{ENaC}$. 
A

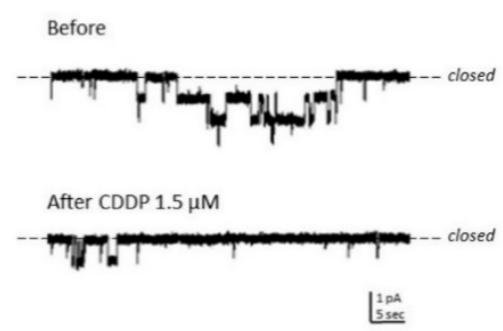

B

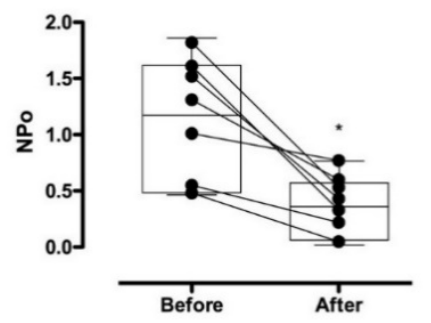

Figure 2. CDDP decreased the activity of the epithelial $\mathrm{Na}^{+}$channel $(\mathrm{ENaC})$ in native murine Principal cells. (A) Representative current traces of $\mathrm{ENaC}$ in cell-attached patches made on the apical plasma membrane of Principal cells in freshly isolated tubules from naïve mice before (top) and after (bottom) treatment with $1.5 \mu \mathrm{M}$ CDDP. Negative pipette potential $-60 \mathrm{mV}$ and inward $\mathrm{Na}^{+}$current downwards. (B) Summary graph of $(n=7)$ paired experiments showing $\mathrm{ENaC}$ activity $\left(\mathrm{NP}_{\mathrm{o}}\right)$ before and after treatment with CDDP. Summary data from experiments were identical to that shown in $(\mathrm{A}) * p<0.05$ vs. Before.

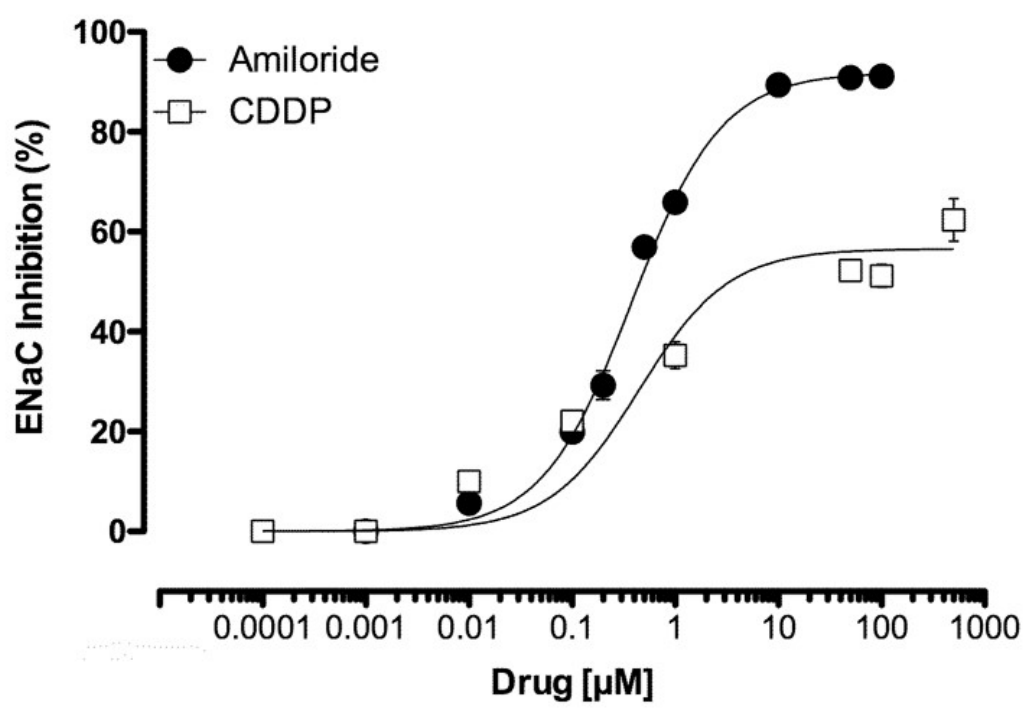

Figure 3. CDDP is a partial inhibitor of ENaC. Summary graph of the dose-dependent inhibitory effects of amiloride (black circles) and cisplatin (white boxes) on mENaC expressed in Chinese Hamster Ovary $(\mathrm{CHO})$ cells $(n=3-5)$. CDDP significantly reduced $\mathrm{ENaC}$ activity with a reduced Emax compared with amiloride.

\subsection{CDDP Competes with Amiloride for Inhibition of ENaC}

We noticed in patch clamp experiments that CDDP seemed to interfere with the amiloride block of the channel. To further explore this, we tested using patch clamp electrophysiology if CDDP competed with amiloride for a block of $\mathrm{mENaC}$ in an overexpression system using $\mathrm{CHO}$ cells. This was done by generating amiloride inhibition curves for $\mathrm{mENaC}$ in the presence of $10 \mu \mathrm{M}$ of CDDP. Figure 4A shows representative macroscopic current traces of $\mathrm{mENaC}$ in the presence of amiloride and amiloride + CDDP. Figure 4B reports summary results of amiloride inhibition curves in the presence and absence of $10 \mu \mathrm{M}$ of CDDP. Treatment with CDDP shifted the amiloride inhibition curve to the right, consistent with CDDP competing with amiloride for a block of the channel. Amiloride is an open channel blocker of the ENaC pore. CDDP showed a typical competitive modulator response with a dextral displacement of the effects of amiloride $\left(\mathrm{IC}_{50}=499 \pm 0.02 \mathrm{nM}\right.$ and $1.59 \pm 0.19 \mu \mathrm{M}$ for amiloride in the absence and presence of CDDP, where ${ }^{*} p<0.05$ vs. amiloride) and a reduced Emax for amiloride $\left(89.58 \pm 1.26\right.$ vs. $67.48 \pm 1.28$ in the absence and presence of CDDP, respectively, where $\left.{ }^{*} p<0.05\right)$. 
A

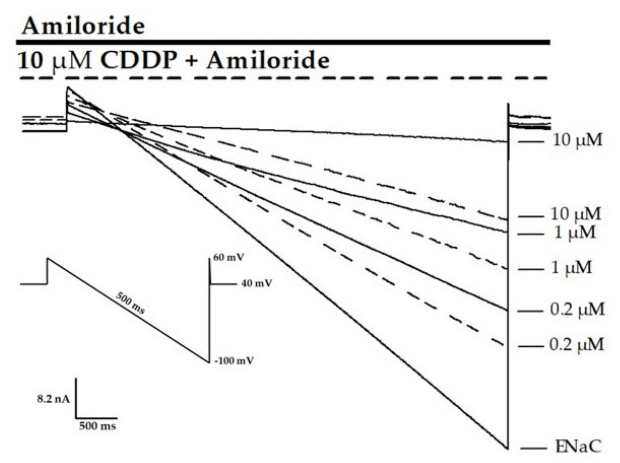

B

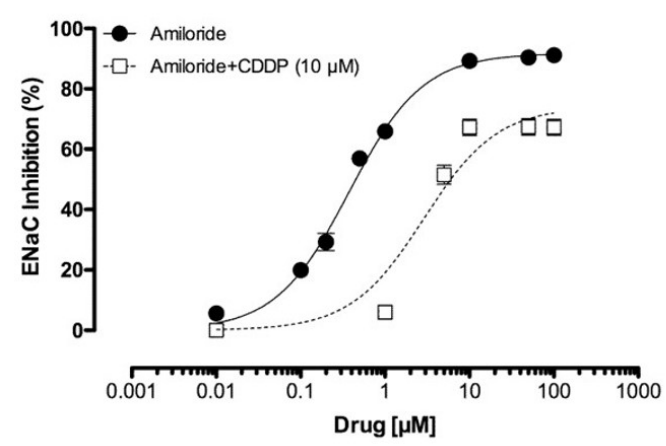

Figure 4. CDDP competes with amiloride, lessening the inhibitory effects of amiloride on ENaC. (A) Overlay of typical macroscopic current traces from a representative $\mathrm{CHO}$ cell expressing $\mathrm{mENaC}$ before and after treatment, with $(0.2-10 \mu \mathrm{M})$ amiloride in the presence (dashed lines) and absence (full lines) of $10 \mu \mathrm{M}$ of CDDP. Currents elicited by voltage ramps were stepped from a holding potential of $40 \mathrm{mV}$ to $60 \mathrm{mV}$ and ramped to $-100 \mathrm{mV}$. (B) Summary graph of ( $n=3-5$ for each amiloride concentration) experiments showing concentration-dependent effects of amiloride on $\mathrm{mENaC}$ in the absence (black circles, full line) and presence (white boxes, dashed line) of $10 \mu \mathrm{M}$ of CDDP. Exposure to CDDP reduced the maximal inhibition percentage of amiloride and caused a dextral displacement of the amiloride inhibition curve.

\section{Discussion}

Our findings confirm that CDDP caused an expected natriuresis. In isolated tubules, CDDP rapidly decreased $\mathrm{ENaC}$ activity. In a heterologous expression system, CDDP decreased the activity of $\mathrm{mENaC}$ in a dose-dependent manner. The inhibition curve for CDDP on ENaC showed this drug to be a partial inhibitor of the channel. CDDP competed with amiloride for the inhibition of ENaC, reducing the effects of this more powerful inhibitor, which suggested that CDDP and amiloride may have overlapping binding sites on the channel.

Cisplatin is an important chemotherapy drug. Possible side effects of CDDP include RSWS [16-19]. As argued above (see Introduction), the inhibition of $\mathrm{ENaC}$ may potentially be contributing to the RSWS caused by CDDP. We began the current study by verifying that CDDP causes natriuresis. As supported by the results in Figure 1, CDDP caused a natriuresis similar to that elicited by the ENaC blocker, BZM. $\mathrm{BZM}$, like all other inhibitors of $\mathrm{ENaC}$, is a weak diuretic due to its ability to increase $\mathrm{Na}^{+}$excretion as a consequence of inhibiting ENaC [20].

Exploring the mechanism underlying this CDDP-dependent natriuresis more deeply, we found, as supported by the results presented in Figures 2 and 3, that CDDP inhibited $\mathrm{ENaC}$ in native distal nephron principal cells and in a heterologous expression system. Importantly, CDDP inhibited ENaC at doses consistent with those used for chemotherapy and causative for RSWS [16,21]. Such observations are consistent with this inhibitory action of CDDP on ENaC possibly being contributory to the RSWS caused by this chemotherapy drug.

CDDP was shown to be a partial inhibitor of $\mathrm{ENaC}$ in the current study, as supported by the results in Figure 3. As demonstrated by the results presented in Figure 4, CDDP competed with amiloride for the inhibition of ENaC. The latter is most consistent with CDDP and amiloride having, at least partially, overlapping binding sites on the channel. It is notable that amiloride is an open pore blocker of ENaC [20]. Future study will be needed to determine if CDDP also is a pore blocker of $\mathrm{ENaC}$, though the current results strongly suggest that it may be.

A close inspection of the molecular structure of CDDP shows that this molecule shares some similarity with the pyrazinoyl guanidine group present in ENaC blockers, such as BZM and amiloride. Perhaps this explains how both could potentially be open channel blockers of ENaC that compete for a common or overlapping binding site. However, such contemplations are tempered by the need 
for further and more precise investigation of this possibility, including a precise mapping of both the amiloride and CDDP binding sites within ENaC.

An alternative explanation of a mechanism consistent with the observation that CDDP is a weak inhibitor of $\mathrm{ENaC}$ that competes with pore blockers of this ion channel is that CDDP contains platinum at its core, and $\mathrm{ENaC}$ is particularly susceptible to the effects of heavy metals. Many heavy metals, including $\mathrm{Cd}^{2+}$ and $\mathrm{Hg}^{2+}$, decrease ENaC activity [15]. However, others including $\mathrm{Zn}^{2+}, \mathrm{Ni}^{2+}$ and $\mathrm{Cu}^{2+}$ increase the activity of ENaC [11]. It is unclear as of yet if the effects of these heavy metals on $\mathrm{ENaC}$ are mediated by actions at the channel pore or if they are allosteric, mediated by a more distal binding site. If the former is true, then perhaps the platinum in CDDP is working in this regard. As stated above, such contemplations are tempered by the limitations of this study and the methods used here to assess CDDP's effects on ENaC. Limitations include a lack of precise information about the specifics of possible direct CDDP interaction with $\mathrm{ENaC}$. A feasible alternative to CDDP directly affecting $\mathrm{ENaC}$ is that $\mathrm{CDDP}$ influences $\mathrm{ENaC}$ activity secondarily to effects on other proteins, possibly including the $\mathrm{Na}^{+} / \mathrm{K}^{+}$-ATPase or the mineralocorticoid receptor. Inhibitory effects of CDDP on both of these proteins have been reported before $[19,22]$.

While the current findings, due to limitations in methodology, cannot discount possible contribution from secondary effects of CDDP on $\mathrm{ENaC}$, we believe the simplest interpretation of the current results is that, in addition to possible secondary effects mediated by inhibition of the $\mathrm{Na}^{+} / \mathrm{K}^{+}$-ATPase and the mineralocorticoid receptor, CDDP also likely has a more direct action on ENaC. Consequently, both the direct and secondary actions of CDDP on ENaC cause the RSWS associated with this important anticancer drug. We make this argument because CDDP affected ENaC in the current study in a heterologous system that did not include a mineralocorticoid receptor. In addition, the spatiotemporal effects of CDDP on $\mathrm{ENaC}$ in the current patch clamp study were rapid and localized to the plasma membrane. The effects of the mineralocorticoid receptor on $\mathrm{ENaC}$ are via transactivation localized to the nucleus, which manifests in minutes to hours. In the current study, CDDP rapidly reduced ENaC activity at the plasma membrane within seconds. Moreover, the competitive nature of $\mathrm{CDDP}$ and amiloride on $\mathrm{ENaC}$ are most consistent with, at least, some direct effect on the channel that is independent of secondary actions mediated by inhibition of the pump.

\section{Materials and Methods}

\subsection{Animals}

All animal use and welfare adhered to the National Institutes of Health Guide for the Care and Use of Laboratory Animals. Protocols were reviewed and approved by the Institutional Animal care and Use Committee of the University of Texas Health Science Center at San Antonio. Mice were housed and cared for in the Laboratory Animal Resources Facility at the University of Texas Health Science Center at San Antonio, which is fully accredited by the Association for Assessment and Accreditation of Laboratory Animal Care and licensed by the United States Department of Agriculture.

\subsection{Metabolic Cage Experiments}

Metabolic cage experiments followed previously published protocols with minor modifications [23]. Briefly, age and weight-matched C57Bl/ 6 male mice ( 2 months old, $24.53 \pm 0.15 \mathrm{~g}$ body weight) were randomly separated into 3 groups: (1) control, (2) CDDP and (3) BZM. Mice were housed socially at 3 mice/cage in metabolic cages (Techniplast, Buguggiate, Italy) and allowed to acclimate with free access to water and food for 2 days. On the third day, mice received an $\mathrm{Na}^{+}$load $(100 \mu \mathrm{L}, 0.9 \% \mathrm{NaCl}$ solution, i.p.) plus treatment with CDDP $(25 \mathrm{mg} / \mathrm{kg}$, i.p.), BZM $(1.4 \mathrm{mg} / \mathrm{kg}$, i.p.) or the vehicle. Urine volume and urinary $\mathrm{Na}^{+}$concentration were evaluated every $2 \mathrm{~h}$ over a $4 \mathrm{~h}$ period. Urinary $\mathrm{Na}^{+}$was quantified with a flame photometer (Jenway, Staffordshire, UK). Animals were observed during the whole time of the experimental period for clinical signs of pain or altered behavior. None were noticed. 


\subsection{Split-Open Tubule Preparation and Single-Channel Patch Clamp Electrophysiology}

Split-open tubules amenable to patch clamp analysis were prepared as previously described [24]. Briefly, mouse kidneys were sectioned transversely. Segments of the connecting tubule (CNT) and cortical collecting duct (CCD) were manually microdissected with forceps and adhered to a glass chip coated with polylysine. These chips were transferred to an inverted microscope, where tubules were split open with sharpened pipettes. Single-channel patch clamp electrophysiology in the cell-attached configuration was then performed on the luminal plasma membranes of the principal cells in these split-opened tubules. The bath solution contained (in $\mathrm{mM}$ ) $150 \mathrm{NaCl}, 5 \mathrm{KCl}, 1 \mathrm{CaCl}_{2}, 2 \mathrm{MgCl}_{2}, 5$ glucose and 10 HEPES (pH 7.4) and the pipette solution contained (in $\mathrm{mM}$ ) $140 \mathrm{LiCl}, 2 \mathrm{MgCl}_{2}$ and $10 \mathrm{HEPES}$ ( $\mathrm{pH}$ 7.4). Channel activity (open probability, $\mathrm{P}_{\mathrm{o}}$, multiplied by channel number $\mathrm{N}$ ) was calculated as previously described [24]. After recording baseline $\mathrm{ENaC}$ activity for $5 \mathrm{~min}$, tubules were treated with CDDP $(1.5 \mu \mathrm{M})$, with ENaC activity quantified in the presence of this drug over the next $5 \mathrm{~min}$. This dose of CDDP showed no toxic effect during the experiments as cell capacitance and input resistances remained constant over the course of these experiments.

\subsection{ENaC Expression in CHO Cells and Whole-Cell Patch Clamp Electrophysiology}

CHO cells were maintained in a culture with Dulbecco's modified Eagle's medium, supplemented with $10 \%$ fetal bovine serum and $1 \%$ penicillin-streptomycin using standard methods [25]. Cells were plated on coverglass chips treated with $0.01 \%$ polylysine. Plated cells were transfected with plasmids encoding $\alpha$-, $\beta$ - and $\gamma$-mouse $\mathrm{ENaC}$ subunits genetically linked to $\mathrm{NH}_{2}$-terminal eCFP using a Polyfect reagent (Qiagen, Valencia, CA) as described previously [26,27]. In brief, $60 \%$ confluent cells in a $35 \mathrm{~mm}$ dish were treated with $2 \mu \mathrm{g}$ of total plasmid cDNA for 24-48 h. Cells were maintained in a culture in the presence of $10 \mu \mathrm{M}$ amiloride, replenished daily. Whole-cell macroscopic current recordings of $\mathrm{mENaC}$ expressed in $\mathrm{CHO}$ cells were made under voltage clamp conditions using standard methods [26-28]. In brief, the current through $\mathrm{ENaC}$ was the inward, amiloride-sensitive $\mathrm{Na}^{+}$current with a bath solution of (in mM) $150 \mathrm{NaCl}, 1 \mathrm{CaCl}_{2}, 2 \mathrm{MgCl}_{2}$ and $10 \mathrm{HEPES}$ (pH 7.4) and a pipette solution of (in mM) $120 \mathrm{CsCl}, 5 \mathrm{NaCl}, 2 \mathrm{MgCl}_{2}, 5$ EGTA, 10 HEPES, 2 ATP and 0.1 GTP (pH 7.4). Current recordings were acquired with an Axopatch $200 \mathrm{~B}$ (Axon Instruments) patch clamp amplifier interfaced via a Digidata 1550 B (Axon Instruments) to a PC running the pClamp 11 suite of software (Axon Instruments). All currents were filtered at $1 \mathrm{kHz}$. Cells were clamped to a $40 \mathrm{mV}$ holding potential with voltage ramps $(500 \mathrm{~ms})$ from 60 down to $-100 \mathrm{mV}$, used to elicit current. ENaC activity is in the amiloride-sensitive current density at $-80 \mathrm{mV}$. Whole-cell capacitance, on average 8-10 pF, was compensated. Series resistance, on average 3-6 megaohms, were also compensated. Cells expressing $\mathrm{mENaC}$ were evaluated by quantifying the macroscopic current in the presence and absence of amiloride. Dose-response curves for amiloride and CDDP were collected. In another set of experiments, cells were exposed to CDDP $(10 \mu \mathrm{M})$ and a dose-response curve for amiloride was then collected. The $\mathrm{EC}_{50}$ and maximal response (Emax), expressed as inhibition (\% inhibition) of channel activity, then were calculated. As stated above, this dose and the time course of CDDP showed no toxic effects for cell capacitance, and input resistances remained constant over the course of these experiments.

\subsection{Statistics}

Values were reported as mean \pm standard error of the mean (SEM). Data were compared by a Student-t-test and a One-way ANOVA, followed by Bonferroni's multiple comparisons test when appropriate and a $p \leq 0.05$ was considered significant.

\section{Conclusions}

In conclusion, we demonstrated here that CDDP decreases ENaC activity, likely via a binding site on the channel that, at least partially, overlaps with that of amiloride. We also confirmed here that 
CDDP causes a natriuresis that is similar to that caused by ENaC blockers. ENaC blockers work as diuretics because they increase sodium excretion. We concluded that the direct inhibitory effect of $\mathrm{CDDP}$ on ENaC contributes to the RSWS caused by this important chemotherapy drug. This action of CDDP appears to be in addition to and separate from the effects of this drug on DNA replication, the mineralocorticoid receptor and $\mathrm{Na}^{+} / \mathrm{K}^{+}$-ATPase.

Author Contributions: A.G.S. and T.M.A.E.-A. contributed equally to this work. A.G.S., C.R.A., J.D.S. and T.M.A.E.-A. designed research; A.G.S., E.M., J.C. and T.M.A.E.-A. performed research; A.G.S., E.M., J.D.S. and T.M.A.E.-A. analyzed data; A.G.S., J.D.S. and T.M.A.E.-A. wrote the paper. All authors have read and agreed to the published version of the manuscript.

Funding: This work was funded by NIH grant numbers R01-DK113816 and R01-DK117909 to J.D. Stockand.

Conflicts of Interest: The authors declare no conflicts of interest.

\section{References}

1. Chu, G. Cellular responses to cisplatin. The roles of DNA-binding proteins and DNA repair. J. Biol. Chem. 1994, 269, 787-790. [PubMed]

2. Siddik, Z.H. Cisplatin: Mode of cytotoxic action and molecular basis of resistance. Oncogene 2003, 22, 7265-7279. [CrossRef] [PubMed]

3. Dasari, S.; Tchounwou, P.B. Cisplatin in cancer therapy: Molecular mechanisms of action. Eur. J. Pharmacol. 2014, 740, 364-378. [CrossRef] [PubMed]

4. Pabla, N.; Dong, Z. Cisplatin nephrotoxicity: Mechanisms and renoprotective strategies. Kidney Int. 2008, 73, 994-1007. [CrossRef] [PubMed]

5. Ciarimboli, G.; Ludwig, T.; Lang, D.; Pavenstädt, H.; Koepsell, H.; Piechota, H.-J.; Haier, J.; Jaehde, U.; Zisowsky, J.; Schlatter, E. Cisplatin Nephrotoxicity Is Critically Mediated via the Human Organic Cation Transporter 2. Am. J. Pathol. 2005, 167, 1477-1484. [CrossRef]

6. Nakamura, T.; Yonezawa, A.; Hashimoto, S.; Katsura, T.; Inui, K.-I. Disruption of multidrug and toxin extrusion MATE1 potentiates cisplatin-induced nephrotoxicity. Biochem. Pharmacol. 2010, 80, 1762-1767. [CrossRef]

7. Huličiak, M.; Vacek, J.; Sebela, M.; Orolinova, E.; Znaleziona, J.; Havlikova, M.; Kubala, M. Covalent binding of cisplatin impairs the function of $\mathrm{Na}(+) / \mathrm{K}(+)$-ATPase by binding to its cytoplasmic part. Biochem. Pharmacol. 2012, 83, 1507-1513. [CrossRef]

8. Šeflová, J.; Cechova, P.; Stenclova, T.; Sebela, M.; Kubala, M. Identification of cisplatin-binding sites on the large cytoplasmic loop of the $\mathrm{Na}(+) / \mathrm{K}(+)$-ATPase. J. Enzym. Inhib. Med. Chem. 2018, 33, 701-706. [CrossRef]

9. Kishore, B.K.; Krane, C.M.; Di Iulio, D.; Menon, A.G.; Cacini, W. Expression of renal aquaporins 1, 2, and 3 in a rat model of cisplatin-induced polyuria. Kidney Int. 2000, 58, 701-711. [CrossRef]

10. Kim, S.W.; Lee, J.U.; Nah, M.Y.; Kang, D.G.; Ahn, K.Y.; Lee, H.S.; Choi, K.C. Cisplatin decreases the abundance of aquaporin water channels in rat kidney. J. Am. Soc. Nephrol. 2001, 12, 875-882.

11. Hanukoglu, I.; Hanukoglu, A. Epithelial sodium channel (ENaC) family: Phylogeny, structure-function, tissue distribution, and associated inherited diseases. Gene 2016, 579, 95-132. [CrossRef] [PubMed]

12. Roush, G.C.; Sica, M.A. Diuretics for Hypertension: A Review and Update. Am. J. Hypertens. 2016, 29, 1130-1137. [CrossRef] [PubMed]

13. Alexander, R.T.; Dimke, H. Effect of diuretics on renal tubular transport of calcium and magnesium. Am. J. Physiol. Physiol. 2017, 312, F998-F1015. [CrossRef] [PubMed]

14. Hunt, T.; Atherton-Watson, H.C.; Axford, J.; Collingwood, S.P.; Coote, K.J.; Cox, B.; Czarnecki, S.; Danahay, H.; Devereux, N.; Howsham, C.; et al. Discovery of a novel chemotype of potent human ENaC blockers using a bioisostere approach. Part 1: Quaternary amines. Bioorganic Med. Chem. Lett. 2012, 22, 929-932. [CrossRef] [PubMed]

15. Yu, L.; Eaton, D.C.; Helms, M.N. Effect of divalent heavy metals on epithelial Na+ channels in A6 cells. Am. J. Physiol. Physiol. 2007, 293, F236-F244. [CrossRef] [PubMed]

16. Hamdi, T.; Latta, S.; Jallad, B.; Kheir, F.; Alhosaini, M.N.; Patel, A. Cisplatin-Induced Renal Salt Wasting Syndrome. South. Med. J. 2010, 103, 793-799. [CrossRef] 
17. Inamori, M.; Inohara, H.; Horii, A. Differential diagnosis of hyponatremia induced by cisplatin-containing chemotherapy: Syndrome of inappropriate secretion of antidiuretic hormone (SIADH) or renal salt wasting syndrome (RSWS). Acta Oto Laryngol. Case Rep. 2016, 1, 33-35. [CrossRef]

18. Pham, P.C.T.; Reddy, P.; Qaqish, S.; Kamath, A.; Rodriguez, J.; Bolos, D.; Zalom, M.; Pham, P.-T. Cisplatin-Induced Renal Salt Wasting Requiring over 12 Liters of 3\% Saline Replacement. Case Rep. Nephrol. 2017, 2017, 1-4. [CrossRef]

19. Iida, T.; Makino, Y.; Okamoto, K.; Yoshikawa, N.; Makino, I.; Nakamura, T.; Tanaka, H. Functional modulation of the mineralocorticoid receptor by cis-diamminedichloroplatinum (II). Kidney Int. 2000, 58, 1450-1460. [CrossRef]

20. Vardanyan, R.; Hruby, V. Synthesis of Essential Drugs. Synth. Essent. Drugs 2006. [CrossRef]

21. Szturz, P.; Wouters, K.; Kiyota, N.; Tahara, M.; Prabhash, K.; Noronha, V.; Adelstein, D.; Van Gestel, D.; Vermorken, J.B. Low-Dose vs. High-Dose Cisplatin: Lessons Learned From 59 Chemoradiotherapy Trials in Head and Neck Cancer. Front. Oncol. 2019, 9, 86. [CrossRef] [PubMed]

22. Sakakibara, N.; Suzuki, K.; Kaneta, H.; Yoshimura, Y.; Deyama, Y.; Matsumoto, A.; Fukuda, H. Inhibition of $\mathrm{Na}+\mathrm{K}+-$ ATPase by cisplatin and its recovery by 2-mercaptoethanol in human squamous cell carcinoma cells. Anti Cancer Drugs 1999, 10, 203-212. [CrossRef] [PubMed]

23. Mironova, E.; Chen, Y.; Pao, A.C.; Roos, K.P.; Kohan, N.E.; Bugaj, V.; Stockand, J.D. Activation of ENaC by AVP contributes to the urinary concentrating mechanism and dilution of plasma. Am. J. Physiol. 2015, 308, F237-F243. [CrossRef] [PubMed]

24. Mironova, E.; Bugay, V.; Pochynyuk, O.; Staruschenko, A.; Stockand, J.D. Recording Ion Channels in Isolated, Split-Opened Tubules. Methods Mol. Biol. 2013, 998, 341-353. [PubMed]

25. Gamper, N.; Stockand, J.D.; Shapiro, M.S. Subunit-Specific Modulation of KCNQ Potassium Channels by Src Tyrosine Kinase. J. Neurosci. 2003, 23, 84-95. [CrossRef] [PubMed]

26. Staruschenko, A.; Adams, E.; Booth, R.E.; Stockand, J.D. Epithelial Na+ Channel Subunit Stoichiometry. Biophys. J. 2005, 88, 3966-3975. [CrossRef]

27. Staruschenko, A.; Nichols, A.; Medina, J.L.; Camacho, P.; Zheleznova, N.N.; Stockand, J.D. Rho Small GTPases Activate the Epithelial Na+ Channel. J. Biol. Chem. 2004, 279, 49989-49994. [CrossRef]

28. Pochynyuk, O.; Staruschenko, A.; Tong, Q.; Medina, J.; Stockand, J.D. Identification of a Functional Phosphatidylinositol 3,4,5-Trisphosphate Binding Site in the Epithelial Na+Channel. J. Biol. Chem. 2005, 280, 37565-37571. [CrossRef] 